This item was submitted to Loughborough's Research Repository by the author.

Items in Figshare are protected by copyright, with all rights reserved, unless otherwise indicated.

\title{
Geometric consistency and stability of consumer-grade digital cameras for accurate spatial measurement
}

PLEASE CITE THE PUBLISHED VERSION

PUBLISHER

(C) Remote Sensing and Photogrammetry Society and Blackwell Publishing Ltd

LICENCE

CC BY-NC-ND 4.0

REPOSITORY RECORD

Wackrow, Rene, Jim H. Chandler, and Paul Bryan. 2019. "Geometric Consistency and Stability of Consumergrade Digital Cameras for Accurate Spatial Measurement”. figshare. https://hdl.handle.net/2134/3608. 
This item was submitted to Loughborough's Institutional Repository by the author and is made available under the following Creative Commons Licence conditions.

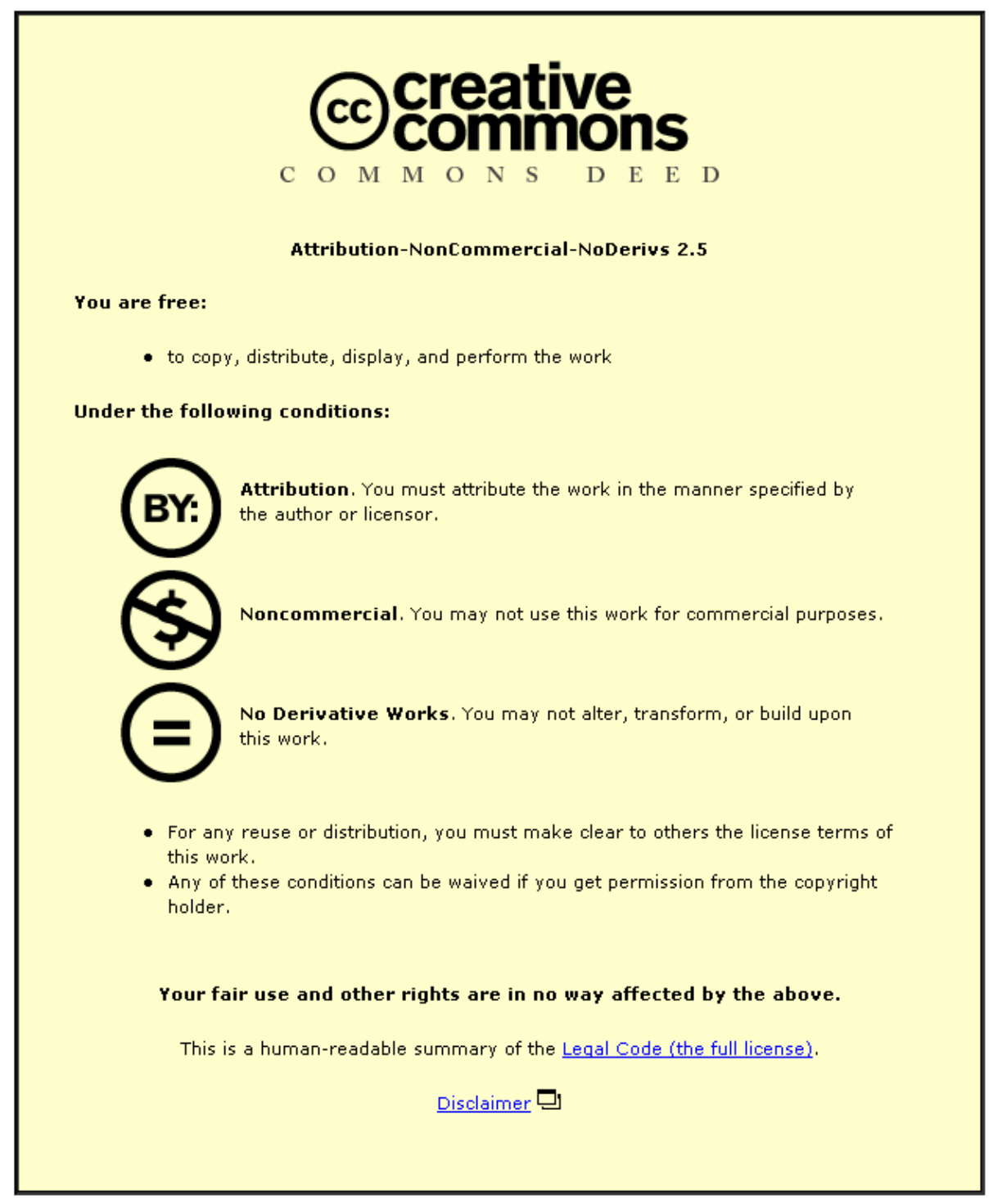

For the full text of this licence, please go to: http://creativecommons.org/licenses/by-nc-nd/2.5/ 


\title{
GEOMETRIC CONSISTENCY AND STABILITY OF CONSUMER-GRADE DIGITAL CAMERAS FOR ACCURATE SPATIAL MEASUREMENT
}

\author{
RENE WACKROW (r.wackrow@lboro.ac.uk), \\ Loughborough University, UK \\ JiM H. CHANDLER (j.h.chandler@lboro.ac.uk), \\ Loughborough University, UK \\ PAUL BRYAN (paul.bryan@english-heritage.org.uk) \\ English Heritage, UK
}

\begin{abstract}
It is known that uncertain internal geometry of consumer-grade digital cameras limits the accuracy of data that can be extracted. These cameras can be calibrated, but the validity of calibration data over a period of time should be carefully assessed before subsequent photogrammetric measurement. This paper examines the geometric stability and manufacturing consistency of a typical low-cost digital camera (Nikon Coolpix 5400) by estimating the degree of similarity between interior orientation parameters (IOP), established over a oneyear period. Digital elevation models (DEMs) are extracted with differing interior orientation parameters (IOP) sets and accuracies are compared using data obtained from seven identical cameras. An independent self-calibrating bundle adjustment (GAP) and the Leica Photogrammetry Suite (LPS) software were used to provide these datasets. Results are presented that indicate the potential of these cameras to maintain their internal geometry in terms of temporal stability and manufacturing consistency. This study also identifies residual systematic error surfaces or "domes", discernible in "DEMs of difference". These are caused by slightly inaccurately estimated lens distortion parameters, which effectively constrain the accuracies achievable with this class of sensor.
\end{abstract}

KEYWORDS: camera calibration, camera stability, digital camera, close range photogrammetry 


\section{INTRODUCTION}

The main advantages of consumer-grade digital cameras are their convenience, portability and low cost. These cameras have not been traditionally used for photogrammetric measurements, owing their uncertain geometry. The uncertainties can be partially resolved by calibration but their temporal stability and manufacturing consistency remain unknown.

During a collaborative project with English Heritage to record rock art in the North East of England (Chandler et al., 2007), seven identical Nikon Coolpix 5400 digital cameras (Fig.1) were calibrated. This provided the opportunity to assess their stability over a one-year period as well as their consistency of manufacture.

Previous work related to calibration of consumer grade cameras is reviewed, before describing the methodology adopted for the study. The link between the stability analyses strategy and the reconstructed object space is introduced followed by experimental results and discussion. Finally, this paper concludes with a brief summary and recommendations for future work.

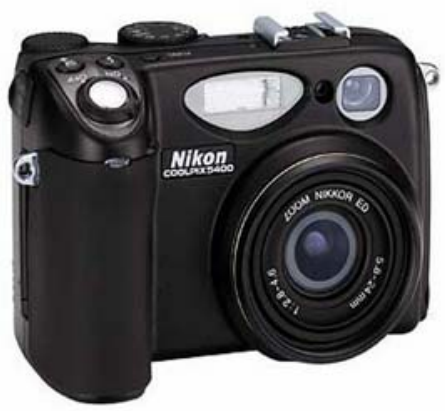

FIG. 1 Nikon Coolpix 5400

\section{Previous Work On CAMERa CALiBration Of CONSUMER-Grade CAMERAS}

Over the past decade, several researchers have assessed the photogrammetric potential of non-metric digital cameras. The Kodak DCS420 and DCS460 have been tested in a variety of photogrammetric applications (Beyer et al. 1995; Brown and Dold, 1995; Fraser et al. 1995; Peipe, 1995; Dold and Peipe, 1996; Miyatsuka, 1996; Schneider, 1996; Shortis et al. 1998; Ahmad and Chandler, 1999) and the use of similar cameras such as the Kodak DC40 has been described in Miyatsuka (1996) and Lichti and Chapman (1997). In addition, the suitability for close range measurement of the Kodak DCS PRO BACK used in conjunction with the Mamiya body was reported in Mills et al. (2003). The accuracy in close range surface measurement between three low-cost consumer-grade digital 
cameras (Sony DSC-P10, Olympus C3030, Nikon Coolpix 3100) and the Kodak DCS460 have been compared in Chandler et al. (2005). All cameras tested revealed potential for use in close range photogrammetry where low to medium accuracy was required. The use of consumer-grade digital cameras for photogrammetric measurements is increasingly accepted in many industrial applications but also in diverse fields ranging from medical and forensic science to architectural work (Fryer, 2007).

The stability of non-metric digital cameras has been reported less frequently in the literature. Shortis et al. (2001) introduced a strategy for accessing the stability of a digital camera by using the ratio of the mean precision of target coordinates to the largest dimension of the target array. Habib and Morgan (2005) attributed the lack of literature to the absence of standards for quantitative analyses of camera stability. An approach based on statistical testing of two sets of interior orientation parameters (IOP) was presented and the disadvantages of this strategy were discussed. Due to the drawbacks of this methodology, a new procedure for stability analysis based on the degree of similarity between the reconstructed bundles using two sets of IOP was introduced. The stability of the Olympus C-5050 digital camera was reported in Bosch et al. (2005). This was achieved by comparing the coordinates of check points with coordinates acquired with a total station. This test was not independent because the same points were used to determine the exterior orientation. Three methodologies (ZROT, ROT and SDR) for evaluating the stability of a camera are presented in Habib et al. (2006). The procedures impose constraints regarding the exterior orientation of the compared bundles. Therefore, each is applicable for a specific geo-referencing technique which describes the position and orientation of the images relative to a coordinate system.

This review of previous work identified the need for an appropriate method to assess the temporal stability and manufacturing consistency of consumer-grade digital cameras. A suitable approach which achieves this objective will be described in this paper.

\section{STABILITY ANALYSES OF SEVEN NIKON COOLPIX 5400 CAMERAS}

Consumer-grade digital cameras have not been designed for measurement so their internal geometry is generally considered unstable (Shortis et al., 1998). The aim of stability analyses is to determine whether the interior orientation of a camera changes over time or not. The methodology adopted initially in this study was to evaluate the degree of similarity between two sets of IOP. In addition, to assess the impact of varying IOPs on accuracy in the object space, which is ultimately of more significance to most users.

\section{The cameras}

Seven Nikon Coolpix 5400 digital cameras were purchased by the Northumberland and Durham Rock Art Project in February 2005 (Barnett, 2006). These have been used regularly by teams of volunteers to systematically record 1500 rock art motifs located in the North of England (Chandler et al., 2007). The 
need to calibrate these seven cameras provided the opportunity to evaluate the stability and consistency of these sensors during normal operation field conditions. It was judged that there was no further need to simulate disturbing impacts of the camera geometry, such as variations in temperature and moisture, external forces of the camera body, use of the auto-focus etc. A benefit of the presence of seven identical cameras also enabled manufacturing consistency to be assessed. A detailed overview of the characteristics of the Nikon Coolpix 5400 camera is given in Table I.

TABLE I. Characteristic of the Nikon Coolpix 5400 Camera

\begin{tabular}{|c|c|}
\hline Feature & Nikon Coolpix 5400 \\
\hline Camera body & compact \\
\hline Resolution [pixel] & 5 million \\
\hline Image size [pixel] & $2592 \times 1944$ \\
\hline Size of sensor $[\mathrm{mm}]$ & $7.18 \times 5.32$ \\
\hline Size of pixel $[\mu \mathrm{m}]$ & $2.77 \times 2.77$ \\
\hline Auto focus & yes \\
\hline Manual focus & yes \\
\hline Dimension [mm] & $108 \times 73 \times 69$ \\
\hline Weight [kg] & 0.4 \\
\hline Cost $[£]$ & 240 (January 2005) \\
\hline
\end{tabular}

The test field

It was expected that the seven cameras would mostly be used at an object distance of $1.5 \mathrm{~m}$ for rock art recording. Therefore a 3D and planar test field was specifically constructed to allow the cameras to be calibrated at this distance. It is an enhancement of the test field used in Chandler et al. (2005) and consists of a medium density fibreboard $(\mathrm{MDF})(1.2 \times 0.9 \mathrm{~m})$ to which eight square blocks of various height and shape were added (Fig. 2). These blocks replicate physical structures such as buildings found in normal vertical aerial photography. To provide an appropriate texture for the image matching algorithm included in the Leica Photogrammetry Suite (LPS) software, the MDF board was painted white and finally splattered with red and blue paint. This test object provides the opportunity of deriving thousands of object measurements and by comparing elevations with their known values, a similar number of check points can be achieved. This allows determining the accuracy in the object space with statistical reliability. In addition, twenty eight photogrammetric target points were distributed over the test field (Fig. 3) and coordinated by theodolite intersection using a Leica TC1010 Total Station (June 2005). The measurements, both horizontal and vertical angles and the distance between the two theodolite stations, were initially computed using basic intersection formula. The estimates of the coordinates of the target points, the measurements derived using a total station and a subset of distances measured with a steel band, were then combined in a least square "variation of coordinates" to determine the best estimates for the photogrammetric target points. These coordinates were used to create a DEM at 1 mm resolution, known as the "Truth DEM". Another set of coordinates was derived by repeating the procedure in May 2006. Both sets of coordinates were 
compared using a 3D similarity transformation. The residuals (maximum $0.5 \mathrm{~mm}$ ) demonstrate the geometric stability of the test field over time and consequently deviations between similarly derived IOPs can not be related to distortion of the MDF base material.

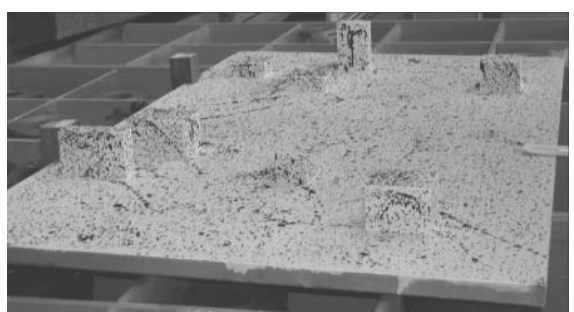

FIG. 2. Test object.

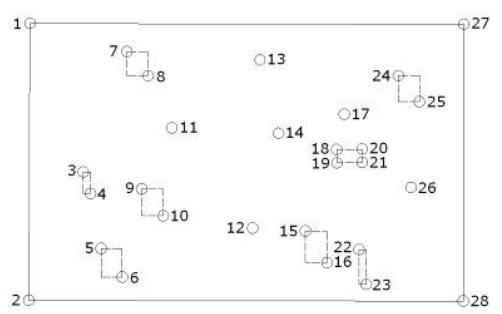

FIG. 3. Position of photogrammetric target points.

\section{Camera calibration}

Determination of the geometric conditions of a camera, described by the IOP, is known as camera calibration. Through the development of computational techniques and the use of non-metric digital cameras for photogrammetric measurements, methods of camera calibration have evolved over the last few decades. The widely used method of self-calibration, where all image observations from various camera view points are used to determine the unknown interior and exterior orientation parameters (Clarke and Fryer, 1998), was adopted in this research.

Six frames, representing the whole test object, were captured with each of the seven cameras at a camera to object distance of approximately $1.5 \mathrm{~m}$ (Fig. 4), with the camera focus set on infinity. The same basic configuration was used for each camera at each time.

For processing the images in LPS, it was essential to initially define the primary orientation of the sensor. The www.dpreview.com website was used to identify the physical size of the sensor and consequently the physical size of each pixel in $\mathrm{X}$ and $\mathrm{Y}$ directions of the CCD array. Once the pixel size and an approximate focal length were defined, the point measurement tool of LPS was used to measure 11 photogrammetric target points manually before 100 tie points were measured using fully automated methods.

Previous work conducted by Chandler et al. (2005) demonstrated that the external self-calibrating bundle adjustment GAP (Chandler and Clarke, 1992) can also be used to estimate the camera parameters and was used in these studies to provide an independent approach to LPS. A familiar eight-parameter model for the bundle adjustment (Kenefick et al., 1972) was available which includes parameters for: principal distance, principal point offset and corrections for radial and decentring distortion. The program can also estimate two additional parameters for affinity and differential scale, but were not found necessary in this study. Avoiding solutions which are over-parameterised is important (Granshaw, 1980; Fraser, 
1982) and the significance of additional parameters was assessed by comparing them with their stochastic properties. This demonstrated that two parameters $\left(k_{1}\right.$, $k_{2}$ ) were significant for modelling radial distortion. However, $k_{3}$ and the parameters $\left(p_{1}, p_{2}\right)$ used for modelling the decentring distortion proved insignificant and were removed. This five-parameter model for the self-calibrating bundle adjustment was maintained for all seven cameras. The derived inner orientation parameters were then re-established into LPS for the purpose of deriving high resolution DEMs and check point data.

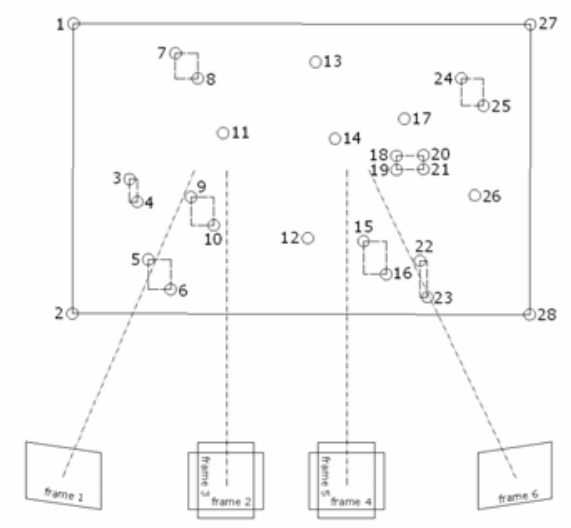

FIG. 4. Image geometry.

\section{DEM generation}

The LPS software was used for DEM generation, which uses a hierarchical feature-based matching algorithm (ERDAS, 2002). Tests revealed that DEMs with optimum accuracy were produced using the following strategy:

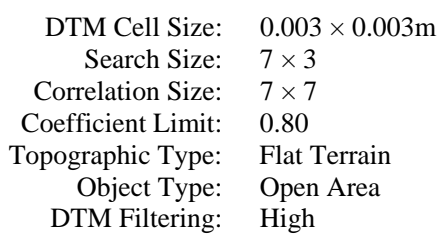

The adaptive capability of LPS to change the search size, correlation size and correlation coefficient limit dynamically during DEM generation was switched off for simplicity.

The automatically extracted DEMs, representing the whole of the physical test object, were compared with the "Truth DEM" by interpolation and subtraction to produce DEMs of difference. As recommended by Li (1988), mean error and standard deviation of error of DEMs of difference were derived using an Erdas Graphical Model. Tests demonstrated that significant areas of inaccurate DEM are situated adjacent to the wooden blocks, which clearly illustrated the shadowing effect of them (Fig. 5). These effects obviously distorted the accuracy statistics. In 
order to avoid this distortion, statistics were also computed for an area of interest which represented the central and flat part of the test object and did not include the wooden blocks. The optimum accuracy for each DEM of difference could consequently be quantified.

\section{RESULTS}

\section{Temporal stability}

The temporal stability of the Nikon Coolpix 5400 camera can be assessed by comparing the degree of similarity between two sets of IOP, established at various dates. Seven identical cameras were calibrated at the $4^{\text {th }}$ of July 2005. This was repeated after four days and after a period of approximately one year. Table II summarises the accuracy of the calibration procedure in terms of accuracy of fit to the control points (restitution accuracy) of camera five. Similar results were achieved with the other six cameras, camera 5 will be used as an exemplar. The first column represents the dates of capturing the images of the test object, whilst the second column tabulates the dates of IOP used for restitution. The rms error $(\mathrm{mm})$ in the object space is summarised in columns three to five and the final two columns represent the rms residuals (pixel) in the image space.

The camera achieved sub-millimetre accuracy (average rms error of $0.3 \mathrm{~mm}$ ), in terms to fit to the control points, whichever combination of image sets and IOP were used. The accuracy statistics indicate no significant variations.

In the image space, accuracies within each set of calibration images varied within the range of approximately 0.1 pixel. However, variations in accuracy at a maximum of 0.4 pixel are noticeable by comparing statistics of different sets of images. This appears to be significant but it must be acknowledged that the automatic tie-point generation tool of LPS was used; which independently creates tie-points in each image set. It is plausible that the discrepancies in accuracy are caused by using different sets of tie-points in each imagery and not by the IOP.

TABLE II. Restitution accuracy by using IOP of different dates

\begin{tabular}{|c|c|c|c|c|c|c|}
\hline \multirow{2}{*}{$\begin{array}{c}\text { Camera/ } \\
\text { Imagery date }\end{array}$} & \multirow[t]{2}{*}{ IOP date } & \multicolumn{3}{|c|}{ Object rms error [mm] } & \multicolumn{2}{|c|}{ Image rms error [pixel] } \\
\hline & & $\mathrm{X}$ & $\mathrm{Y}$ & $\mathrm{Z}$ & $\mathrm{X}$ & $\mathrm{y}$ \\
\hline \multicolumn{7}{|l|}{ Cam 5} \\
\hline $4^{\text {th }}$ July 2005 & $4^{\text {th }}$ July 2005 & 0.3 & 0.2 & 0.4 & 0.63 & 0.55 \\
\hline $4^{\text {th }}$ July 2005 & $8^{\text {th }}$ July 2005 & 0.2 & 0.2 & 0.2 & 0.63 & 0.57 \\
\hline $4^{\text {th }}$ July 2005 & $12^{\text {th }}$ July 2006 & 0.5 & 0.4 & 0.4 & 0.68 & 0.69 \\
\hline $8^{\text {th }}$ July 2005 & $8^{\text {th }}$ July 2005 & 0.4 & 0.2 & 0.3 & 0.80 & 0.82 \\
\hline $8^{\text {th }}$ July 2005 & $4^{\text {th }}$ July 2005 & 0.2 & 0.2 & 0.3 & 0.79 & 0.85 \\
\hline $8^{\text {th }}$ July 2005 & $12^{\text {th }}$ July 2006 & 0.4 & 0.3 & 0.4 & 0.90 & 0.87 \\
\hline $12^{\text {th }}$ July 2006 & $12^{\text {th }}$ July 2006 & 0.4 & 0.3 & 0.4 & 0.96 & 0.82 \\
\hline $12^{\text {th }}$ July 2006 & $4^{\text {th }}$ July 2005 & 0.3 & 0.2 & 0.4 & 0.94 & 0.83 \\
\hline $12^{\text {th }}$ July 2006 & $8^{\text {th }}$ July 2005 & 0.3 & 0.2 & 0.4 & 0.97 & 0.85 \\
\hline
\end{tabular}


This would suggest that there is a high degree of consistency between all sets of IOP for this camera exemplar. A similar result was obtained with the other six cameras.

Table III summarises the accuracy of DEM generation generated by using different combinations of sets of imagery and IOP at various dates for camera five within the two areas of the test object. Similar results were again obtained with the other six cameras. As expected, the cameras achieved poor accuracies for the full test area. These were caused by the small number of gross failures for points adjacent to the wooden blocks. Mean errors for the central area of interest varied between 0.5 to $2.5 \mathrm{~mm}$ and did not follow expectations. Even more surprisingly, optimum restitution accuracy were not achieved by generating DEMs using frames and IOP from the same date. This leads to the conclusion that the central area of extracted DEMs were perhaps affected by the same systematic error source, an issue discussed later in this paper.

TABLE III. DEM accuracy by using IOP of different dates

\begin{tabular}{|c|c|c|c|}
\hline $\begin{array}{c}\text { Camera/ } \\
\text { Imagery date }\end{array}$ & IOP date & $\begin{array}{c}\text { Full area } \\
\text { (mean error } \pm \text { standard } \\
\text { deviation) }[\mathrm{mm}]\end{array}$ & $\begin{array}{c}\text { Central area } \\
\text { (mean error } \pm \text { standard } \\
\text { deviation) }[\mathrm{mm}]\end{array}$ \\
\hline \multicolumn{4}{|r|}{ - } \\
\hline $4^{\text {th }}$ July 2005 & $4^{\text {th }}$ July 2005 & $0.5 \pm 7.2$ & $1.8 \pm 0.9$ \\
\hline $4^{\text {th }}$ July 2005 & $8^{\text {th }}$ July 2005 & $0.4 \pm 5.8$ & $1.1 \pm 0.7$ \\
\hline $4^{\text {th }}$ July 2005 & $12^{\text {th }}$ July 2006 & $0.9 \pm 7.1$ & $2.5 \pm 0.7$ \\
\hline $8^{\text {th }}$ July 2005 & $8^{\text {th }}$ July 2005 & $0.9 \pm 6.1$ & $1.4 \pm 0.8$ \\
\hline $8^{\text {th }}$ July 2005 & $4^{\text {th }}$ July 2005 & $0.6 \pm 6.9$ & $1.3 \pm 1.0$ \\
\hline $8^{\text {th }}$ July 2005 & $12^{\text {th }}$ July 2006 & $1.2 \pm 5.8$ & $1.9 \pm 0.8$ \\
\hline $12^{\text {th }}$ July 2006 & $12^{\text {th }}$ July 2006 & $0.3 \pm 6.0$ & $1.6 \pm 0.7$ \\
\hline $12^{\text {th }}$ July 2006 & $4^{\text {th }}$ July 2005 & $-0.1 \pm 6.6$ & $0.5 \pm 0.9$ \\
\hline $12^{\text {th }}$ July 2006 & $8^{\text {th }}$ July 2005 & $-0.2 \pm 5.6$ & $0.7 \pm 0.7$ \\
\hline
\end{tabular}

\section{Manufacturing consistency}

The presence of seven identical Nikon Coolpix 5400 digital cameras provided the opportunity to assess their manufacturing consistency. Three sets of IOP, originally derived with camera four in calibration sessions of various dates, were used in conjunction with the six calibration frames, captured with camera five on the $4^{\text {th }}$ of July 2005. The restitution accuracy achieved for these two cameras, which provide a representative sample for the results obtained from all cameras, are presented in Table IV. Particularly, no significant discrepancies were observable in accuracy statistics (average object rms error of $0.3 \mathrm{~mm}$; variation of image rms error of 0.22 pixel) comparing these configurations. It is notable that there is a high degree of similarity between sets of IOP which certainly demonstrates remarkable geometric consistency achieved by the manufacturer.

The accuracy in the object space, achieved by extracting DEMs using the configurations presented above, are summarised in Table V. It indicates again a poor DEM accuracy estimated for the whole test object and discrepancies between 0.6 to $2.1 \mathrm{~mm}$ for the central test area. By comparing the DEM accuracy statistics presented in Table III and Table V, it is notable that camera five achieved a 
similar accuracy level, even though IOP sets derived from a different camera were used. This again demonstrates a high degree of manufacturing consistency for this type of camera.

TABLE IV. Restitution accuracy by using IOP of different cameras/dates

\begin{tabular}{|c|c|c|c|c|c|c|}
\hline \multirow{2}{*}{$\begin{array}{c}\text { Camera/ } \\
\text { Imagery date }\end{array}$} & \multirow{2}{*}{$\begin{array}{l}\text { Camera/ } \\
\text { IOP date }\end{array}$} & \multicolumn{3}{|c|}{ Object rms error [mm] } & \multicolumn{2}{|c|}{ nage rms error [pixel] } \\
\hline & & $\mathrm{X}$ & $\mathrm{Y}$ & Z & $\mathrm{X}$ & $\mathrm{y}$ \\
\hline Cam 5 & Cam 5 & & & & & \\
\hline $4^{\text {th }}$ July 2005 & $4^{\text {th }}$ July 2005 & 0.3 & 0.2 & 0.4 & 0.63 & 0.55 \\
\hline Cam 5 & Cam 4 & & & & & \\
\hline $4^{\text {th }}$ July 2005 & $4^{\text {th }}$ July 2005 & 0.4 & 0.2 & 0.2 & 0.68 & 0.75 \\
\hline $4^{\text {th }}$ July 2005 & $8^{\text {th }}$ July 2005 & 0.4 & 0.2 & 0.4 & 0.78 & 0.77 \\
\hline $4^{\text {th }}$ July 2005 & $7^{\text {th }}$ June 2006 & 0.4 & 0.3 & 0.4 & 0.62 & 0.57 \\
\hline
\end{tabular}

TABLE V. DEM accuracy by using IOP of different cameras/dates

\begin{tabular}{|c|c|c|c|}
\hline $\begin{array}{c}\text { Camera/ } \\
\text { Imagery date }\end{array}$ & $\begin{array}{l}\text { Camera } \\
\text { IOP date }\end{array}$ & $\begin{array}{c}\text { Full area } \\
\text { (mean error } \pm \text { standard } \\
\text { deviation) }[\mathrm{mm}]\end{array}$ & $\begin{array}{c}\text { Central area } \\
\text { (mean error } \pm \text { standard } \\
\text { deviation) }[\mathrm{mm}]\end{array}$ \\
\hline $\begin{array}{l}\text { Cam } 5 \\
4^{\text {th }} \text { July } 2005\end{array}$ & $\begin{array}{l}\text { Cam } 5 \\
4^{\text {th }} \text { July } 2005\end{array}$ & $0.5 \pm 7.2$ & $1.8 \pm 0.9$ \\
\hline $\begin{array}{l}\text { Cam } 5 \\
4^{\text {th }} \text { July } 2005\end{array}$ & $\begin{array}{l}\text { Cam } 4 \\
4^{\text {th }} \text { July } 2005\end{array}$ & $0.5 \pm 6.6$ & $1.6 \pm 0.6$ \\
\hline $4^{\text {th }}$ July 2005 & $8^{\text {th }}$ July 2005 & $-0.3 \pm 6.8$ & $0.6 \pm 0.6$ \\
\hline $4^{\text {th }}$ July 2005 & $7^{\text {th }}$ June 2006 & $0.7 \pm 7.1$ & $2.1 \pm 0.9$ \\
\hline
\end{tabular}

\section{DISCUSSION}

\section{DEM generation and accuracy statistic}

Figures 5 to 7 represent DEMs of difference for the full test object using the imagery from the $4^{\text {th }}$ of July 2005 and IOP sets derived using the $4^{\text {th }}, 8^{\text {th }}$ July 2005 and $12^{\text {th }}$ July 2006 imagery, acquired with camera five. Sets of IOP were achieved using the GAP calibration approach (Chandler et al., 2005). Areas in DEMs with elevations less than $-5 \mathrm{~mm}$ are illustrated by solid red colour, solid green regions indicate height differences greater than $+5 \mathrm{~mm}$ and white areas represent regions of no height differences between the "truth DEM" and automatically extracted DEMs.

Difference images clearly indicate significant areas of inaccurate DEM which can be classified into four types. Obviously, the DEM generation algorithm of the LPS software has difficulties in extracting information representing the wooden blocks situated on the left and lower right area of the test object. The dimensions are $70 \times 30 \times 100 \mathrm{~mm}$ (left block) and $105 \times 30 \times 72 \mathrm{~mm}$ (lower right block) which simulates isolated tall buildings, which perhaps explains these difficulties. Furthermore, areas with gross errors within the near vicinity of the wooden blocks clearly indicate the shadowing effect of them, which is to be expected. The effect on the numerical statistics can be noticed by comparing the standard deviation (average value $6.3 \mathrm{~mm}$ ) determined for the full test area with the standard 
deviation (average value $0.8 \mathrm{~mm}$ ) for the central region which does not include the wooden blocks. The other obvious areas of inaccurate DEM are the distinctive radial "domes", slightly shifted to the left and the systematic "contour" pattern to the right of the centre of the DEM. These systematic effects will be accounted for in the next section.

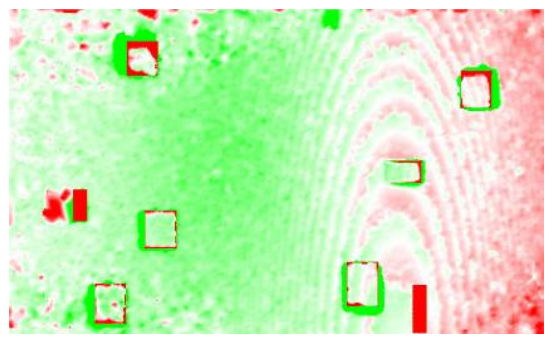

FIG. 5. Elevation differences-IOP: $4^{\text {th }}$ July 2005.

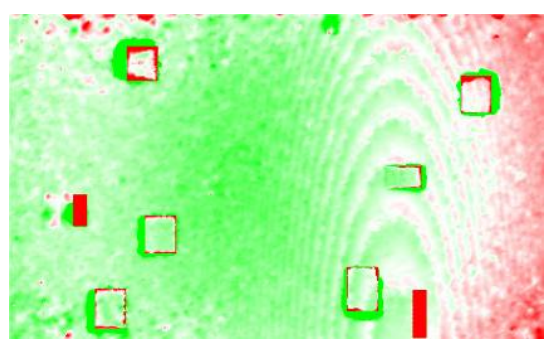

FIG. 7. Elevation differences-IOP: $12^{\text {th }}$ July 2006.

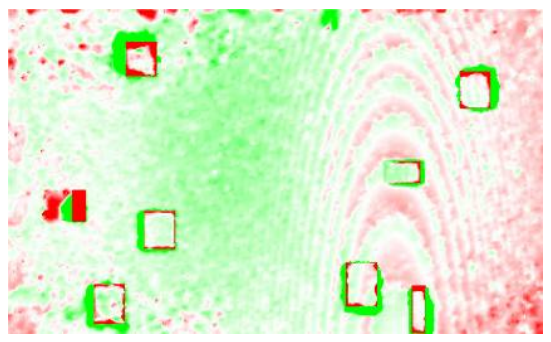

FIG. 6. Elevation differences-IOP: $8^{\text {th }}$ July 2005

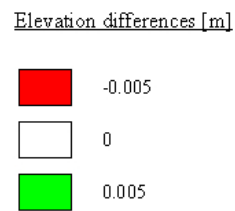

\section{Systematic pattern in difference images}

A hierarchical feature-based matching algorithm that incorporates both pyramid layers and an epipolar constraint to reduce the search time for conjugate points in image pairs is used by LPS for DEM generation (ERDAS, 2002). This approach generates a systematic "contour" pattern using a base to distance ratio of 1:7 for an image pair, illustrated in Fig. 5 to 7. However, tests have shown that changing the base to distance ratio to 1:2 reduces this systematic effect, as demonstrated in Fig. 8. The software manufacturer Leica Geosystems was contacted in November 2006 and this unusual effect reported. However, no explanation accounting for this pattern so far has been received (May 2007). Tests conducted with another DEM generation package (ERDAS OrthoMax) created a dome but no such systematic contour pattern. 

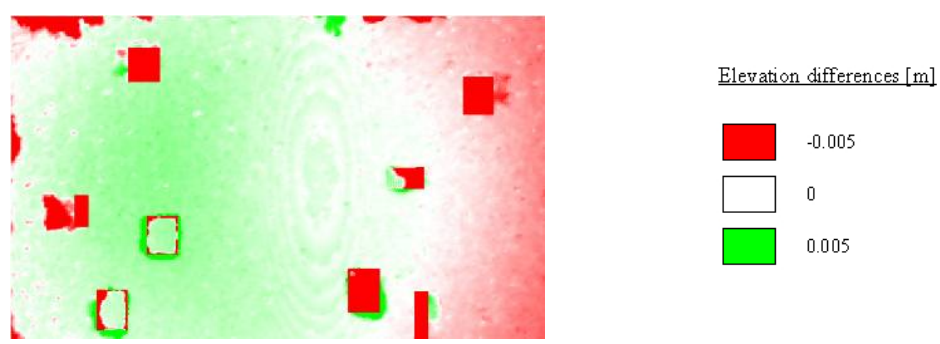

FIG. 8. Difference image with base to distance ratio of $1: 2$

\section{“Dome” structure in DEM of difference}

Fig. 5 to 8 represent DEMs of difference for the full test object where distinctive radial "domes" appear to be approximately located to the left of the centre of DEMs. They are caused by residual systematic effects arising from slightly inaccurate radial lens distortion parameters and have been also noted in past work (Stojic et al., 1998; Chandler et al., 2003; 2005). A theoretical proof explaining them was given in Fryer and Mitchell (1987). This confirms that any uncorrected residual $x$ parallaxes will create a systematic offset in computed elevations, causing a flat object to appear curved.

The radial domes (maximum elevation of $2 \mathrm{~mm}$ ) clearly affect the accuracy statistic estimated for the central test object. The achieved accuracy for the sensors is approximately $1.4 \mathrm{~mm}$ (average mean error) for the central area tested. By removing these systematic errors in difference images, the cameras will be certainly capable of achieving an improved accuracy, perhaps approaching the theoretical optimum of $0.5 \mathrm{~mm}$ at this camera object distance of $1.5 \mathrm{~m}$.

The variation in radial lens distortion for sensor 5 using various sets of IOP are shown in Fig. 9. The differences between these curves and the mean curve never exceed $7 \mu \mathrm{m}$ and even these extremes were achieved at the very edges of the image format. These results correspond closely with the findings of Robson and Gyory (2006) in which the variations in distortion for eight sensors of a panoramic camera cluster have been investigated.

Reviewing the results summarised in Table II to V and Fig. 9, the cameras achieved similar accuracy whichever combination of camera and IOP has been used. This level of accuracy is suitable for routine measurement of textured surfaces and DEM generation to an accuracy of $2 \mathrm{~mm}$. Tests have demonstrated remarkable temporal stability and manufacturing consistency of the cameras. Variations in calibration parameters for these sensors are generally not significant when they are used at the level of accuracy described. This finding agrees with the experimental camera calibration tests carried out by Remondino and Fraser (2006). 


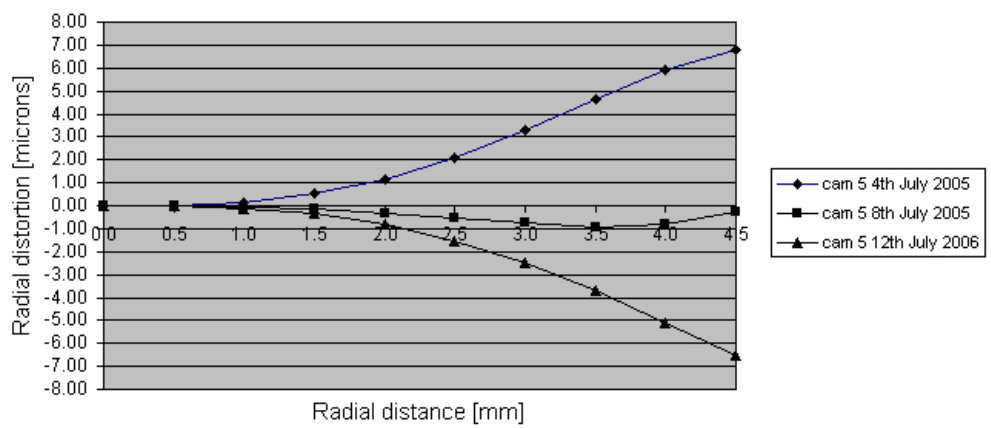

FIG. 9. Radial distortion curves showing differences with respect to a mean curve for camera five and three sets of IOP

\section{CONCLUSION}

The work presented in this paper has explored and identified successfully the temporal stability and manufacturing consistency of the Nikon Coolpix 5400 digital camera over a one-year period. This type of camera is capable of generating DEMs to an accuracy of $1.4 \mathrm{~mm}$, from a distance of $1.5 \mathrm{~m}$ using IOP derived though self calibration using imagery obtained by any of these cameras. This result is highly significant, as it implies that a "generic" distortion curve may well be applicable for all Nikon 5400 cameras (based on our sample of seven). In addition, such accuracies could be suitable for many applications. This paper also identified existing systematic errors in difference images which are caused by slightly inaccurate lens distortion parameters being estimated by the selfcalibration approach. These effectively constrains the accuracies achievable. Further experimental work will be conducted to see if it is possible to reduce these effects and will be reported in a future paper.

\section{ACKNOWLEDGEMENTS}

The authors would like to acknowledge the work of Dr. Tertia Barnett, formerly Chair of the Northumberland and Durham Rock Art Project (Northumberland County Council) and also the Engineering and Physical Sciences Research Council (EPSRC) for the first author's studentship.

\section{REFERENCES}

AHMAD, A. and CHANDLER, J.H., 1999. Photogrammetric capabilities of the Kodak DC40, DCS420 and DCS460 digital cameras. Photogrammetric Record, 16(94): 601-615.

BARnETT, T., 2006. Northumberland and Durham Rock Art Project.

http://pscm.northumberland.gov.uk/pls/portal92/docs/2091.pdf [Accessed 10th August, 2006]. 
BEYER, H.A., UfFENKAMP, V. and VAN DER VLUGT, G., 1995. Quality control in industry with digital photogrammetry. Optical 3-D Measurement Techniques III (Eds. A. Gruen and H. Kahmen). Wichmann, Heidelberg, 533 pages: 29-38.

BosCH, R., KÜLÜR, S. and GÜLCH, E., 2005. Non-metric camera calibration and documentation of historical buildings. CIPA XX International Symposium, Torino, 990 pages: 142-147.

BROWN, D.C. and DOLD, J., 1995. V-STARS- a system for digital industrial photogrammetry. Optical 3-D Measurement Techniques III (Eds. A. Gruen and H. Kahmen). Wichmann, Heidelberg, 533 pages: $12-21$.

CHANDLER, J.H. and CLARK, J.S., 1992. The archival photogrammetric technique: further application and development. Photogrammetric Record, 14(80): 241-247.

CHANDLER, J.H., BufFIN-BÉLANGER, T., RICE, S., REID, I. and GRAHAM, D.J., 2003. The accuracy of a river bed moulding/casting system and the effectivness of a low-cost digital camera for recording river bed fabric. Ibid., 18(103): 209-223.

ChANDLER, J.H., FRYER, J.G. and JACK, A., 2005. Metric capabilities of low-cost digital cameras for close range surface measurement. Ibid., 20(109): 12-26.

Chandler, J.H., Bryan, P. and Fryer, J.G., 2007. The development and application of a simple methodology for recording rock art using consumer-grade digital cameras. Ibid., 22(117): 10-21.

CLARKE, T.A. and FRYER, J.G., 1998. The development of camera calibration methods and models. Ibid., 16(91): 51-66.

DOLD, J. and PIEPE, J., 1996. High resolution data acquisition to observe moving objects. International Archives of Photogrammetry and Remote Sensing, 31(B5): 471-474.

ERDAS, 2002. Imagine OrthoBase user's guide. Leica Geosystems, Atlanta. 483 pages: 341.

FRASER, C.S., 1982. Film unflatness effects in analytical non-metric photogrammetry. International Archives of Photogrammetry and Remote Sensing, 24(5): 156-166.

FRASER, C.S., SHORTIS, M.R. and GANCI, G., 1995. Multi-sensor system self-calibration. Videometrics IV. SPIE 2598, : 2-18.

FRYER, J.G. and MitCHELl, H.L., 1987. Radial distortion and close range stereophotogrammetry. Australian Journal of Geodesy, Photogrammetry and Surveying, 46/47: 123-138.

FrYeR, J.G., MiTCHELL, H. and CHANDLER, J.H., 2007. Applications of 3D measurement from images. Whittles Publishing, Caithness. 384 pages.

GRANSHAW, S.I., 1980. Bundle adjustment methods in engineering photogrammetry. Photogrammetric Record, 10(56): 181-207.

HaBIB, A. and MoRgAN, M., 2005. Stability analysis and geometric calibration of off-the-self digital cameras. Photogrammetric Engineering \& Remote Sensing, 71(6): 733-741.

Habib, A., Pullivelli, A., Mitishita, E., Ghanma, M, and Kim, E-M., 2006. Stability analysis of low-cost digital cameras for aerial mapping using different georeferencing techniques. Photogrammetric Record, 21(113): 29-43.

KENEFICK, J.F., GYER, M.S. and HARP, B.F., 1972. Analytical self-calibration. Photogrammetric Engineering, 38(11): 1117-1126.

LI, Z., 1988. On the measure of digital terrain model accuracy. Photogrammetric Record, 12(72): 873877.

LiCHTI, D.D. and CHAPMAN, M.A., 1997. Constrained FEM self calibration. Photogrammetric Engineering \& Remote Sensing, 63(9): 1111-1119.

MiLlS, J.P., SCHNEIDER, D., BARBER, D.M. and BRYAN, P.G., 2003. Geometric assessment of the Kodak DCS pro back. Photogrammetric Record, 18(103): 193-208.

MiYATSUKA, Y., 1996. Archaeological real-time photogrammetric system using digital still camera. International Archives of Photogrammetry and Remote Sensing, 31(B5): 374-377.

PIEPE, J., 1995. Photogrammetric investigation of a $3000 \times 2000$ pixel high resolution still video camera. Ibid., 30(5W1): 36-39.

Remondino, F. and FrASER, C., 2006. Digital camera calibration methods: considerations and comparisons. International Archives of Photogrammetry, Remote Sensing and Spatial Information Sciences,36(5): 266-272.

RoBSON, S. and GYORY, G., 2006. OpTag - a combined panoramic photogrammetric and radio frequency tagging system for monitoring passenger movements in airports. Ibid.: at http://www.isprs.org/commission5/proceedings06/paper/1262_Dresden06.pdf [Accessed 29th November, 2006] 
SCHNEIDER, C-T., 1996. DPA-WIN-a PC based digital photogrammetric station for fast and flexible on-site measurement. International Archives of Photogrammetry and Remote Sensing, 31(B5): 530-533.

SHORTIS, R.M., RoBSON, S. and BEYER, H.A., 1998. Principal point behaviour and calibration parameter models for Kodak DCS cameras. Photogrammetric Record, 16(92): 165-186.

SHORTIS, R.M., OGLEBY, C.L, ROBSON, S., KARALIS, E.M. and BEYER, H.A., 2001. Calibration modelling and stability testing for the Kodak DC200 series digital still camera. Videometrics and Optical Methods for 3D Shape Measurements. SPIE 4309,: 148-153.

StoJic, M. ChANDleR, J.H., AshmoRe, P. and LUCE, J., 1998. The assessment of sediment transport rates by automated digital photogrammetry. Photogrammetric Engineering \& Remote Sensing, 64(5): 387-395.

\section{Zusammenfassung}

Es ist allgemein bekannt, dass die unsichere innere Geometrie von digitalen Amateurkameras die Genauigkeit der extrahierten Daten limitiert. Diese Kameras können zwar kalibriert werden, aber die Gültigkeitsdauer dieser Kalibrierungsparameter sollte vor der Verwendung für photogrammetrische Zwecke sorgfältig überprüft werden. Diese Veröffentlichung betrachtet die geometrische Stabilität und die Fertigungsstabilität einer typischen kostengünstigen digitalen Kamera (Nikon Coolpix 5400) durch Beurteilung des Ähnlichkeitsgrades der inneren Orientierungsparameter, welche über einen Zeitraum von einem Jahr ermittelt wurden. Die ermittelten inneren Orientierungen von sieben identischen Kameras wurden benutzt, um digital Höhenmodelle zu extrahieren und ihre Genauigkeiten zu vergleichen. Ein unabhängiges Programm zur Bündeltriangulation (GAP) sowie die Leica Photogrammetry Suite (LPS) Software wurden benutzt, um diese Daten bereitzustellen. Ergebnisse werden präsentiert, welche das Potential dieser Kameras zeigen, ihre geometrische Stabilität und Fertigungsstabilität beizubehalten. Diese Studie identifiziert Oberflächen mit systematischen Fehlern oder „Kuppeln“, sichtbar in dem Differenzbetrag von digitalen Höhenmodellen. Diese werden durch ungenau berechnete radiale Verzeichnungsparameter verursacht und limitieren die erreichbare Genauigkeit mit diesen Sensoren. 